\title{
INVENTÁRIO DA OFERTA TURÍSTICA: REFLEXÕES TEÓRICAS PARA O PLANEJAMENTO E ORDENAMENTO DO ESPAÇO TURÍSTICO
}

\author{
Inventario de oferta turística: reflexiones teóricas para la planificación y ordenación del espacio turístico. \\ Tourist offer inventory: knowledge for planning and ordering the touristic space
}

Aguinaldo César Fratucci

Universidade Federal Fluminense (UFF), Brasil

DOI: https://doi.org/10.18472/cvt.20n1.2020.1783 Redalyc: http://www.redalyc.org/articulo.oa? acfratucci@id.uff.br id $=115462634002$

Claudia Corrêa de Almeida Moraes

Universidade Federal Fluminense (UFF), Brasil

claudiamoraes@uol.com.br

Recepción: 03 Noviembre 2019

Aprobación: 20 Febrero 2020

\section{Resumo:}

Entre as ações para o planejamento e o ordenamento dos espaços apropriados para o turismo está o conhecimento dos elementos que o compõem. Uma das metodologias para se obter este conhecimento é a do Inventário da Oferta Turística (IOT). Este artigo se propóe a descortinar o uso desta metodologia na obtenção de conhecimentos que possibilitem auxiliar o desenvolvimento de etapas e de intervençóes no território por meio do planejamento turístico. A pesquisa utilizou dados coletados em fontes selecionadas, tanto bibliográficas como documentais, referentes ao tema e de quatro décadas de experiência profissional dos autores em projetos vinculados a elaboração e implementação de IOTs em diversos destinos turísticos brasileiros. O resultado reconfirmou a importância da metodologia do IOT para o planejamento e ordenamento do território, porém notou-se que esta percepção não é comungada por todos os agentes sociais do turismo, seja pela sua desatualização frente às necessidades contemporâneas e/ou pela inexistência ou pela inventariação insuficiente em muitos destinos turísticos. Também se observou que as políticas públicas demonstraram pouca relevância à metodologia ou a deturparam ao tratá-la apenas como um banco de dados.

Palavras-ChaVE: Planejamento Turístico, Inventário da Oferta Turística, Espaço turístico; IOT-RJ.

\section{Abstract:}

Among the actions to planning and ordering of the appropriate spaces for tourism, it is essential to know the elements that compose it. One of the methodologies to obtain this knowledge is the Tourism Offer Inventory (IOT). This article aims to reveal the use of this methodology in acquiring knowledge that allows help to the development of stages and interventions in the territory through tourism planning. The research used data collected from selected sources, both bibliographic and documentary, referring to the theme and in the last four decades the professional experience of the authors in projects linked to the development and implementation of IOTs in several Brazilian tourist destinations. The result reconfirmed the importance of the IOT methodology for planning and ordering the territory. However, it was noted that this perception is not shared by all social agents of tourism, either for its dispute in the face of contemporary needs and/or the lack of existence or insufficient inventory in many tourist destinations. It was also observed that public policies show little relevance to the methodology or misrepresented it when treating it as just a database.

KEYWORDS: Tourism planning, Tourist offer inventory. Tourist space; IOT-RJ.

Palabras Clave: Planificación turística, Inventario de oferta turística, Espacio turístico; IOT-RJ

\section{INTRODUÇÃ̃}

O planejamento turístico é concebido com o desígnio de realizar intervenções e ordenação no território. Para Fratucci (2000, p. 122), "É no lugar turístico que o fenômeno turístico se materializa e sobrepõe suas formas fixas e pelas peculiaridades do fenômeno, em alguns momentos ocorre simultaneamente”. O lugar turístico reúne o espaço e o território. O turismo se apropria de espaços específicos e os transforma. Ao fazê-lo, segundo Souza (1995), produz territórios e territorialidades flexíveis e descontínuas. O processo de transformação do 
espaço e da produção de territórios baseados no fenômeno turístico, se denomina processo de turistificação. (Knafou, 1996).

Desta forma, o planejamento e o ordenamento turístico são desenvolvidos de maneira racional, usando diferentes recursos, ferramentas e processos de organização, gestão e monitoramento de formas específicas, com finalidades próprias dos agentes envolvidos (Carvalho \& Pimentel, 2013). Ele preconiza que seus objetivos sejam orientados em prol do desenvolvimento econômico, social, cultural e ambiental, no sentido de se obter os benefícios esperados e justificar sua importância. Por conseguinte, os métodos e técnicas de planejamento escolhidos influenciam no processo e na gestão do turismo.

Uma das ferramentas que subsidia os estudos de planejamento turístico é o inventário da oferta turística (IOT). Ele oferece informações atualizadas e sistematizadas sobre o locus da produção e do consumo do produto turístico. Fratucci (2000, p.122), considera que o "produto turístico é entendido como a soma dos atrativos turísticos, dos equipamentos e serviços turísticos, da infraestrutura de apoio e de todas as suas interações e interrelações, conforme proposto por Boullón (1990) e Beni (2004)”.

A transformação do patrimônio material e imaterial de um determinado trecho do espaço turístico em oferta turística é um processo complexo que exige um estudo detalhado e cuidadoso. De tal modo, preocupamo-nos em demonstrar como é este percurso do processo de turistificação (Knafou, 1996) e quais são as etapas e intervenções necessárias para que o resultado seja um produto turístico competitivo e coerente com as ansiedades e desejos da sociedade e do mercado contemporâneo. Estas informações auxiliam na transformação dos recursos em recursos turísticos e, posteriormente, em produtos turísticos ou na requalificação destes produtos.

Como um sistema de informações, ele ultrapassa o papel de ser apenas um banco de dados. A coleta e o tratamento dos dados são a sua primeira função. Durante esta fase, os resultados dos levantamentos são inseridos sistematicamente em um ambiente de armazenamento de dados. A sistematização dos dados e a sua transformação em informações, permitirá que haja consultas que subsidiem estudos e análises. Logo, a inventariação é muito mais complexa que a geração do banco de dados, pois os dados inventariados necessitam de análises e interpretações que levem à tomada de decisões visando o planejamento turístico.

Considerando este cenário, o presente artigo se propõe a analisar o uso desta metodologia na obtenção de conhecimentos que possibilitem auxiliar o desenvolvimento de etapas e de intervenções no território por meio do planejamento turístico Para desenvolvê-lo, optamos por empregar referências selecionadas na literatura turística nacional e internacional que tratam dos temas: inventário da oferta turística, produto turístico, planejamento turístico e território turístico e levarmos em consideração a experiência profissional obtida, nas últimas quatro décadas, por seus autores diretamente vinculados a projetos de implantação de inventários de oferta turística em diversos municípios brasileiros.

\section{O PLANEJAMENTO TURÍSTICO E A TURISTIFICAÇÃo DOS ESPAÇOS}

O planejamento e o ordenamento dos espaços apropriados para o turismo a partir das ações específicas de cada grupo de agentes sociais que o produzem (Fratucci, 2008) envolve o trabalho de equipes multidisciplinares com conhecimento dos elementos componentes deste espaço, sejam eles materiais ou imateriais, naturais ou produzidos pelo trabalho do homem. Por isso, para realizar propostas de intervenção, há necessidade de um grupo multivariado de profissionais (Chias, 2007; Vals, 2006; Petrocchi, 2001; Beni, 2004).

Destarte, algumas metodologias para mapeamento, identificação e levantamento desses elementos têm sido propostas e aplicadas em diferentes lugares, como será apontada na próxima seção. No entanto, antes convém revermos como ocorrem os processos de construção dos espaços turístificados, ou visto de outra maneira, como um determinado trecho do espaço obtém a posição de oferta turística para ser disponibilizado no mercado e consumido por turistas. 
Tal processo envolve muitas variáveis e intervenções de diferentes agentes sociais em vários momentos. Fratucci $(2008$, 2014a) explicita que o processo de turistificação é bastante complexo, envolvendo relações e interrelações entre diferentes grupos de agentes sociais interessados no acontecer do turismo. Esses agentes sociais podem ser identificados a partir de cinco grupos: a) os visitantes/turistas; b) os agentes do mercado/ empreendedores; c) o poder público (em seus diferentes níveis); os trabalhadores do setor (diretos e indiretos) e d) os moradores das áreas onde o turismo se manifesta concretamente (centros receptores ou destinos turísticos).

A combinação recursiva e complementar (Morin, 1999) das ações de cada um desses agentes sociais resulta nos processos de turistificação e dão concretude ao fenômeno turístico contemporâneo. Mesmo que as ações de alguns desses grupos sejam mais evidentes (especialmente dos visitantes/turistas e dos empresários), não se deve menosprezar a intensidade e a importância da ação dos outros agentes sociais indicados, pois cada um, com sua lógica específica de territorialização, contribui para a construção daquilo que é denominado de espaço do turismo (Boullón, 2002).

Entendemos que o espaço do turismo é mais amplo e complexo do que o espaço do visitante/turista (Fratucci, 2008) por ser resultado da sobreposição dos espaços apropriados pelos diferentes agentes sociais apontados que, sincronicamente, se territorializam em um mesmo trecho do espaço, articulando territóriosredes específicos. O somatório desses territórios-redes constrói o território do turismo (ou o espaço turístico) que, por suas características, sempre será descontínuo, composto por pontos e trechos do espaço que são articulados e modificados pelos diferentes agentes sociais que produzem o turismo.

Conhecer e entender tais processos de territorialização e de transformação do espaço (aqui compreendido como uma produção social) (Santos, 1996) requer metodologias próprias e estas que, por sua vez, devem oferecer a oportunidade para os planejadores identificarem as possibilidades ainda imanentes de construção de produtos turísticos consistentes e competitivos que, após devidamente formatados, serão oferecidos (oferta turística) ao mercado consumidor selecionado estrategicamente.

Por conseguinte, como é esse percurso que transforma uma parte do patrimônio material e imaterial de um determinado trecho do espaço em oferta turística? Para responder essa indagação construímos um esquema básico (Figura 1), fundamentado nas propostas de alguns autores (Chias, 2007; Petrocchi, 2001, dentre outros), na intenção de sintetizar o processo e permitir a compreensão de cada estágio da turistificação. 


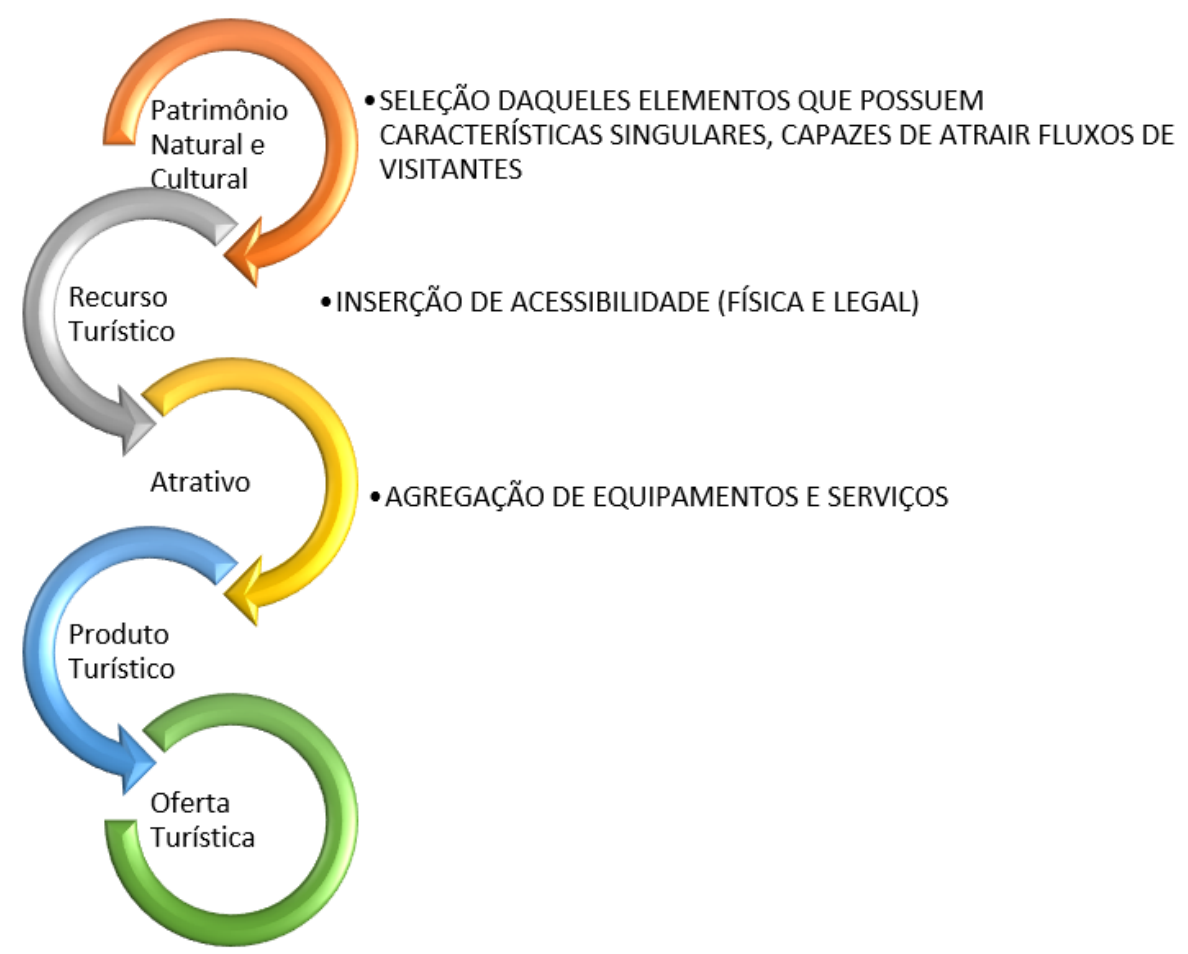

Figura 1 -Esquema Explicativo das Etapas de Criação da Oferta Turística Fratucci (2019)

O esquema finaliza com a Oferta Turística, que para Beni (2017) é entendida como:

Constituída pelo conjunto de bens e de serviços que são oferecidos ao consumo do turista, disponibilizando um amplo leque de produtos que abrange tanto o setor terciário (transportes, setores bancários, seguros etc.) como o setor secundário (instalações, infraestrutura, construção civil etc.) e, também, o setor primário (bens agrícolas para transformação e para alimentação). Para que haja o deslocamento de visitantes e o desfrute destes recursos naturais, será necessária infraestrutura de acesso, banheiros, lanchonetes, restaurantes, entre outros estabelecimentos que ofereçam suporte para a chegada e a permanência no destino (Beni, 2017, s.p.).

Para se chegar à oferta, inicialmente deve-se identificar e selecionar os recursos turísticos, compreendidos pela Organização Mundial do Turismo (OMT) como "todos os bens e serviços que por intermédio da atividade do homem e dos meios que conta, tornam possíveis a atividade turística e a satisfação das necessidades da demanda" (OMT, 1993, p.43), que possam tornar capazes de atrair fluxos de visitantes.

Esta primeira etapa é fundamental e deve ser realizada com critérios elaborados de tal forma que possibilite oferecer ao planejador segurança para a escolha e definição de qual recurso será transformado em atrativo turístico.

Os atrativos, de acordo com Valls (2006), são os elementos que desencadeiam o turismo, estando relacionado ao despertar do interesse do público pelo destino. Porém, eles somente atingem a condição de produto turístico se forem agregados de serviços e equipamentos necessários para sua fruição. Desta feita, os atrativos quando envoltos pelos serviços e equipamentos, com todas as questões políticas, econômicas, sociais e ambientais determinados pela sociedade contemporânea, formam um produto que pode ser oferecido ao mercado.

O produto turístico é definido por Balanzá \& $\operatorname{Nadal}(2003$, p. 68) como “a combinação de bens e serviços, de recursos [atrativos] e infraestruturas, ordenados de forma que ofereçam vantagens ao cliente, que consigam satisfazer suas motivações e expectativas, e que estejam disponíveis para serem consumidos pelos turistas". Esses produtos formam a oferta turística. "A organização da oferta turística por meio da formatação de seus 
atrativos em produtos turísticos se reveste, portanto, de importância estratégica para o desenvolvimento de destinos" (Barbosa, 2011, p. 21).

No contexto do processo de planejamento não é somente a metodologia de pesquisa da oferta turística que deve ser adequadamente desenvolvida, mas também o profissional que dela fará uso. Este terá que possuir formação específica, advindo dessa necessidade, a presença de um bacharel em turismo com uma visão (o "olhar do turismólogo") de todo o processo para coordená-lo, sendo apoiado por outros profissionais que possam dar segurança aos seus diagnósticos, como geógrafos, historiadores, antropólogos, biólogos, arquitetos, entre outros, formando uma equipe multidisciplinar.

\section{A IMPortânCia dA METODOlogia do INVENTARio dA OFERTA TURÍSTICA}

A necessidade de se conhecer a realidade turística de um território para planejá-lo fez com que originassem as metodologias de classificação e caracterização dos elementos formadores da oferta turística. Estas pesquisas de levantamentos turísticos foram elaboradas no formato de inventários que permitem identificar e obter informações sobre os recursos, definir critérios e marcos conceituais para sua valorização. Estes são analisados, interpretados e discutidos para tornar-se instrumentos do planejamento turístico.

Vale destacar que, nas políticas públicas de turismo do Brasil, a importância e a necessidade do IOT para os processos de desenvolvimento turístico são explicitadas desde a década de 1950 (Fratucci, 2014a). A Lei Geral do Turismo (2008) estabeleceu a Política Nacional de Turismo (PNT) e reconfirmou a importância e a necessidade do IOT em seu artigo $5^{\circ}$. O texto da PNT apresenta como um dos seus objetivos "implementar o inventário do patrimônio turístico nacional, atualizando-o regularmente" e recomenda que todos os municípios brasileiros, independente de tamanho, localização ou número de habitantes, tenham os seus IOTs. Este inventário tem a função de ser um diferencial quando o município se candidata a receber verbas específicas direcionadas pelo MTur (Brasil, 2008) e por governos estaduais.

No estado de São Paulo, por exemplo, os municípios que são considerados legalmente como Estâncias Turísticas[1] tem prerrogativa de receberem aportes financeiros específicos para o incentivo ao turismo. Para conseguirem este status, devem encaminhar, entre os documentos a serem apresentados ao Poder Legislativo, três inventários: o dos atrativos turísticos, o dos equipamentos e serviços turísticos e o da infraestrutura de apoio turístico (São Paulo, 2015).

Em Minas Gerais, a apresentação do inventário da oferta turística atualizado de cada município componente do Circuito Turístico é um dos pré-requisitos para certificação. A certificação é dada pela Secretaria de Estado de Turismo e precisa ser renovada anualmente, garantindo a atualização dos dados.

No entanto, as autoras fazem uma crítica a este pré-requisito para a certificação. Se por um lado é uma forma de forçar os municípios a criar ou atualizar o IOT, caso já tenham, a exigência faz com que muitos não sejam bem elaborados, apenas realizados para cumprir o requisito.

Portanto, só ter um inventário para constar no processo, ou tê-lo com qualidade discutível, não trará o benefício que ele proporciona. Poderia ser proposto desenvolver critérios que garantissem a sua qualidade para obter a certificação. Mas, no processo de descentralização, a responsabilidade deve recair nos gestores do processo do turismo municipal e regional e não em organismos centralizados.

Desde a década de 60 do século XX, a metodologia do IOT é conhecida no Brasil, no entanto, muitos planejamentos turísticos ocorrem sem que esta etapa do processo seja realizada. Desenvolver destinos e produtos sem estudos mais aprofundados sobre seu patrimônio turístico pode gerar produtos turísticos com qualidade inferior no âmbito da competitividade, afetar o desenvolvimento do turismo e ampliar as consequências indesejáveis procedentes deste fenômeno. 


\subsection{Breve percurso histórico dos enfoques dos inventários turísticos no Brasil}

A primeira edição em língua portuguesa do IOT, em Portugal, foi escrita por Cunha em a "Hierarquização das Estâncias Termais Portuguesas" (Cunha, 1973). Já no Brasil, ocorre um pouco mais tarde, em 1977, quando o Governo Brasileiro por meio da Empresa Brasileira de Turismo (EMBRATUR) apresenta o documento considerado o pioneiro oficial de abrangência nacional, o "Sistema Integrado de Planejamento Turístico" (BRASIL, 1977). Havia a preocupação com os inventários da oferta turística e a proposta foi baseada na metodologia da Organização dos Estados Americanos (OEA).

Um ano depois, a Organização Mundial do Turismo (OMT) publica a "Evaludacion de los Recursos Turísticos", documento que passou a ser o modelo de avaliação da oferta turística para os países de língua espanhola e portuguesa. Em 1993, seguindo esta linha, Leno Cerro (1993) apresenta a metodologia da OEA em seu Centro de Capacitação Turística (CICATUR) para identificar o potencial turístico. Esta metodologia visa definir quais são os recursos que deveriam receber investimentos e, para tanto, além do levantamento e armazenagem dos dados, estes são avaliados e hierarquizados em grau de maior importância pela sua atratividade seguindo indicadores específicos. Cria-se assim, um ranking de atrativos segundo os critérios estabelecidos pela metodologia.

No Brasil, Pinto \& Moesch em "Inventariação Turística: por um modelo de superação metodológica" (2006) abordam três projetos iniciados a partir de 1960. O primeiro, Tourism Project of Brazil, no governo de Juscelino Kubitschek, o segundo, também na citada década, da empresa Consórcio Tecnibéria \& Ingevix, coordenado pela Superintendência do Desenvolvimento da Região Sul (SUDESUL) e o terceiro, com a metodologia da OMT-OEA e pelo Centro Ibero-Americano de Capacitação Turística (CICATUR). Sendo o último projeto explicitado sua origem e a sua disseminação pelas autoras neste trecho,

Equivale a dizer da Organização Mundial do Turismo para a Organização dos Estados Americanos, adaptada pelo Centro Ibero-Americano de Capacitação Turística, abraçado pela EMBRATUR, Instituto Brasileiro de Turismo e, irradiado para todos os órgãos oficiais de turismo de cada estado do país, os quais por sua vez também submeteram a ferramenta recomendada a adaptações de conveniências locais (Pinto \& Moesch, 2006).

Surgem, então, as propostas oficiais da Embratur (1977 e 1993) e, depois, as do Ministério do Turismo (MTur) de 2006 e 2011 que contém os mesmos princípios, apenas atualizando a metodologia.

A promulgação da Lei 6.513 de 20 de dezembro de 1977, que dispõe sobre a criação de Áreas Especiais e de Locais de Interesse Turístico e sobre o inventário com finalidades turísticas dos bens de valor cultural e natural, a Embratur [...] deveria definir as Áreas Especiais e os locais considerados de Interesse Turístico, sempre com o objetivo de se definirem os bens culturais e naturais protegidos, que possam ter utilização turística e os usos turísticos compatíveis com os mesmos bens (Fratucci, 2014, p.52).

Com esse dispositivo legal oficialmente, o inventário da oferta turística tornou-se o referencial básico para o processo de definição e delimitação das áreas e dos locais de interesse turísticos (Fratucci, 2014a). No território nacional, o projeto piloto para executar o inventário da oferta turística ocorreu no município de Mangaratiba (RJ), no âmbito da implantação do projeto "Identificação do Espaço Turístico Nacional" (EMBRATUR, 1979, p.3). Uma equipe composta por técnicos no Centro Brasileiro de Informação Turística da EMBRATUR e da Diretoria de Planejamento da Companhia de Turismo do Estado do Rio de Janeiro (FLUMITUR) aplicaram a metodologia proposta, no sentido de corrigi-la e complementá-la, antes de seu repasse para todos os órgãos estaduais de turismo (Fratucci, 2005).

Esses processos são difundidos por autores brasileiros que escreveram sobre planejamento turístico como: Barreto (2009), Beni (2003; 2017), Braga (2013), Dias (2003), Fernandes (2011), Ignarra (2013), Petrocchi (2009), Ruschmann (2003), entre outros, que em suas obras trataram a respeito dos inventários turísticos. Também existem autores que publicaram livros específicos sobre IOT usando modelos adaptados da metodologia da OEA: Bissoli (1999), Dencker (2007), Stigliano \& Cesár (2006) e Lopes (2015). Embora 
possa haver algumas alterações nos itens a serem inventariados, a estrutura de todas estas publicações baseiase na mesma matriz de classificação da oferta turística da OEA. Apesar das revisões e atualizações, o modelo predominante para o IOT no Brasil ainda é a do MTur inspirado no da OMT-OEA/CICATUR, não obstante das críticas realizadas, por exemplo, por Peratroni, Silva \& Nagabe (2012) e Madureira \& Haag (2011) sobre as dificuldades do uso da metodologia como instrumentos de coleta de dados (formulários) para o conteúdo do IOT.

Propostas de complementações e atualizações, como a de Moraes, Raimundo \& Garcia (2000) foram aplicadas ao estudo "Turismo no Alto e Médio Tietê: possibilidades e infraestrutura". Nesse caso específico, os autores executaram o primeiro estudo de planejamento regional no Brasil com o uso das técnicas de georreferenciamento, ferramenta que, atualmente, é muito imprescindível nos IOTs.

Versões mais contemporâneas sobre o uso da técnica do georreferenciamento foram implantadas por Lima, Godinho Azevedo \& Teixeira (2011). Eles usaram o mapeamento turístico georreferenciado para a inventariação, alterando a metodologia de coleta. Fernandes (2000), por sua vez, inova ao desenvolver um ambiente inteligente com base em redes neurais artificiais multicritério, que auxiliam na tomada de decisão e de investimentos turísticos, modificando as propostas de modos de decisão anteriores. Aparecem sugestões para estudos de áreas específicas como a de Gutíerrez \& Fernández-Martínez (2010). Os autores indicam a adaptação da metodologia da OMT/OEA para lugares de interesse geológico.

$\mathrm{Na}$ área cultural, Pires (2000) avalia e altera a proposta de Leno Cerro (1993) de limitações inerentes à classificação pela via da fragmentação. Ele usa o Fator de Ponderação mediante a introdução de três elementos: conectividade, concentração de recursos e oferta de alojamento, criando o método que denominou de Alavancagem Múltipla, sendo aceito com algumas críticas por Camargo (2001).

O conceito geral de cognição alcança todas as formas de conhecimento, incluídos a percepção, o raciocínio e o julgamento. Assim, Ladwig (2010) propõem o uso de mapas cognitivos, entendidos como representações gráficas de conjuntos de reproduções discursivas (informações coletadas no inventário) feitas por um sujeito (o ator) com vistas a um objeto (o problema), em contextos de interações particular (Cossete \&Audet, 1992) para fazer a análise dos inventários por meio de software específicos.

Para a coleta e análises de dados são propostas outras metodologias como a participativa. Esta proposta vai ao encontro com a de Varisco et al (2014), do Programa Nacional de Municipalização do Turismo (PNMT, 1996) ou a de Bartholo Junior \& Egrejas (2014) com a metodologia dos roteiros de visitação em sítios de interesse turístico a partir de diálogos com moradores, frequentadores e trabalhadores que os tomam como Sítios Simbólicos de Pertencimento, entre tantos outros.

Esses são alguns dos exemplos de propostas ou de análises frente ao modelo da OMT/OEA na tentativa de melhorá-las ou adaptá-la às novas necessidades.

Oficialmente no Brasil, o modelo de IOT esteve em vigência até 2013, sendo sua última atualização em 2011. O citado modelo foi base para a construção de um Banco de Dados Digital Nacional dos Inventários da Oferta Turística alocado no site do MTur. Depois da desativação do projeto do MTur, todos os dados ficaram desatualizados, finalizando-se a proposta de um banco de dados nacional. Esse banco nunca conseguiu atingir sua totalidade.

Alguns estados brasileiros possuem metodologias específicas e equipe própria para desenvolver os inventários. Em outros, a obrigação é dos destinos turísticos que, quando o executam, o fazem de diversas maneiras com equipes próprias, consultores externos ou com convênio com universidades. Em suma, atualmente no Brasil não há uma política unificada sobre a maneira como se deve fazer a inventariação da oferta, o que pode ser um sinalizador da ausência de compreensão da importância desta ação para garantir processos de desenvolvimento de destinos turísticos sustentáveis e competitivos. Sem o conhecimento sistemático e atualizado dos os elementos que compóem a oferta turística de um destino, torna-se difícil oferecer produtos atualizados, sustentáveis e competitivos para o mercado consumidor. 


\section{CONSIDERAÇões FINAIS}

Como indicado na introdução, o desafio colocado por essa reflexão era estudar o IOT como uma ferramenta metodológica para o planejamento e ordenamento territorial do espaço turistificado. Entendemos este planejamento e ordenamento como realizado por grupos de agentes sociais que se apropriam dos espaços para o turismo, por meio de intervenções realizadas por equipes multidisciplinares, cabendo aos envolvidos, a compreensão, a ação e a responsabilidade por estas intervenções e suas consequências tanto positivas como negativas.

Destarte, algumas metodologias para mapeamento, identificação e levantamento desses elementos têm sido alvitradas e aplicadas em diferentes países, no sentido de responder a pergunta: o que um destino turístico possui e quais as valorações dos seus atrativos, equipamentos e serviços turísticos que podem ser estruturados como oferta turística e utilizados para promover e atender a demanda turística?

Ao estudar as etapas de criação da oferta turística observa-se o percurso a seguir do recurso até chegar ao produto turístico e, depois, à oferta. Este processo necessita de subsídios de conhecimentos para ser executado e uma maneira de obtê-lo pode ser com o auxílio de metodologias para inventários turísticos.

Como aborda Smith (1992), há uma dificuldade ao realizar uma investigação descritiva de lugares, sendo esta complexa, de múltiplas facetas e de numerosas propostas. Esta afirmação é corroborada por Almeida (2006), para quem os fins acabam gerando métodos específicos, sendo que estes métodos podem ser agrupados em três categorias principais: descrição da localização de instalações e atividades, inventário de recursos e descrição das imagens das regióes e seus recursos.

Verificamos que, embora já sejam amplamente divulgadas as metodologias do inventário turístico, elas não são utilizadas em muitos casos no processo de planejamento turístico.

Não se ter o conhecimento sistemático e atualizado do território, pela ausência da aplicação correta da metodologia, pode resultar num produto turístico não atualizado, insustentável e não competitivo frente às demandas contemporâneas, fazendo com que o destino turístico empregue esforços em vão de recursos financeiros, humanos e técnicos, além dos resultados negativos não esperados que poderão advir.

Deste modo, as novas propostas de adaptação da metodologia, críticas e sugestões, ainda não se tem uma avaliação e um parecer que seja compatível com as necessidades do planejamento turístico contemporâneo, sendo imprescindível desenvolvê-la. Porém, de nada adiantará uma nova metodologia se não houver a sensibilização dos gestores públicos acerca da sua necessidade e da preparação adequada de seu uso.

Um inventário é uma ferramenta que deve ser atualizada constantemente para que o gestor possa ter informações atualizadas na tomada de decisões. Embora possa ser dispendioso obter este conhecimento em sua primeira edição, depois da base montada e com métodos de coletas que garanta dados frequentemente renovados, o custo e o tempo despendido serão bem menores e tornar-se-á uma rotina no contexto do planejamento e da gestão do turismo.

Certamente estamos conscientes das limitações do estudo e que ainda precisamos de outras reflexões mais aprofundadas sobre a metodologia do inventário da oferta turística e sua aplicabilidade no planejamento e ordenamento do território turístico.

\section{REFERÊNCIAS}

Almeida, M. V. (2006). Matriz de Avaliação do Potencial Turístico de Localidades Receptoras. Tese (Doutorado) Departamento de Relaçóes Públicas, Propaganda e Turismo, Escola de Comunicações e Artes, Universidade de São Paulo.

Balanzá, I. M. \& Nadal, M.C. (2003). Marketing e Comercialização de Produtos Turísticos. São Paulo: Pioneira Thomson Learning.

Barbosa, L.G. (Org). (2011). Estudo de competitividade de produtos turísticos. - Brasília, DF: SEBRAE. 
Barreto, M. (2005). Planejamento responsável do turismo. Campinas: Papirus

Beni, M. C. (2004). Análise Estrutural do Turismo. 10 ed. São Paulo: Senac.

Beni, M. C. (2017). Análise Estrutural do Turismo. 14 ed. São Paulo: Senac. e-book.

Bissoli, M. Â. M. A. (1999). Planejamento turístico municipal com suporte em sistemas de informação. São Paulo: Futura.

Boullón, R. C. (2002). Planejamento do espaço turístico. Bauru, SP: Edusc.

Braga, D. (2006). Planejamento Turístico. Teoria e Prática. Rio de Janeiro: Campus

Brasil. Ministério do Turismo. (2008). Lei 11.771. Diário Oficial da União. 19 de setembro de 2008.

Brasil. Ministério da Indústria e do Comércio; Empresa Brasileiro de Turismo (Embratur). (1997). II Reunião do Sistema Nacional de Turismo. Rio de Janeiro: Embratur.

Camargo, H. (2001). Turismo e Patrimônio Cultural. In: Camargo, H.et al. I Jornada de Turismo, Meio Ambiente e Patrimônio Cultural, 2001, São Paulo. Resumo do Seminário I Jornada de Turismo, Meio Ambiente e Patrimônio Cultural. São Paulo, SP: Aleph/ MJ Livros. p. 65-74.

Cavalcante, J. (2016). Inventário Turístico: sua importância para o desenvolvimento local de Boa Vista/RR. Textos e Debates, Boa Vista, 30, 39-54, jul/dez.

Chias, J. (2007). Turismo, o negócio da felicidade: desenvolvimento e marketing turístico de países, regiões, lugares e cidades. São Paulo: Senac.

Cossette, P.\& Audet, M. (1992). Mapping of an Idiosyncratic Schema. Journal of Management Studies. 29 (3), 325-348.

Cunha, L (1973). Hierarquização das Estâncias Termais Portuguesas. Lisboa: [s.n.].

Dencker, A. F. M. (2007). Pesquisa em Turismo: planejamento, métodos e técnicas. São Paulo: Futura.

Dias, R. (2003). Planejamento do Turismo. Política e desenvolvimento do turismo no Brasil. São Paulo: Atlas.

EMBRATUR. Empresa Brasileira de Turismo. (1979). Identificação do Espaço Turístico Nacional. Rio De Janeiro: Embratur (mimio.).

EMBRATUR, Empresa Brasileira de Turismo. (1984). Metodologia do inventário da oferta turística. Rio de Janeiro. 168p. (mimio.).

Fernandes, A. (2000). DIAGTUR - Ambiente Inteligente para Análise de Inventários Turísticos Dissertação (doutorado em geografia) - Engenharia da Produção, Universidade Federal de Santa Catarina, Florianópolis.

Gutierrez, I. \& Fernandez-Marintez, E. (2010). Geosites Inventory in the Leon Province (Northwestern Spain): A Tool to Introduce Geoheritage into Regional Environmental Management. Geoheritage, 2 (1), 57-75.

Fratucci, A. C. (2000). O ordenamento territorial da atividade turística no Estado do Rio de Janeiro: processos de inserção dos lugares turísticos nas redes do turismo. Dissertação (mestrado em geografia) - Instituto de Geociências, Universidade Federal Fluminense, Niterói-RJ.

Fratucci, A. C. (2005). A formação e o ordenamento territorial do turismo no Estado do Rio de Janeiro a partir da década de 1970. In; Bartholo, R.; Delamaro, M.\& Badin, I. (org.). (2005). Turismo e sustentabilidade no Rio de Janeiro. Rio de Janeiro: Garamont. 81-90.

Fratucci, A. C. (2008). A dimensão espacial nas políticas públicas brasileiras de turismo: as possibilidades das redes regionais de turismo. Niterói-RJ: UFF, 308 f. Tese (doutorado), Programa de Pós-graduação em Geografia, Universidade Federal Fluminense, Niterói-RJ.

Fratucci, A. C. (2014a). A dimensão espacial das políticas públicas de turismo no Brasil. In.: Pimentel, T; D.; E., M. L. \& Tomazzoni, E. L (org.). (2014). Gestão Pública do turismo no Brasil: teorias, metodologias e aplicações. Caxias do Sul/RS: Educs, 39-64.

Fratucci, A. C. (2014b). Turismo e território: relações e complexidades. Caderno Virtual de Turismo. Edição especial: Hospitalidade e políticas públicas em turismo. Rio de Janeiro, 14, supl.1, 87- 96.

Ignarra, L. R. (2013). Fundamentos do Turismo. 3a ed. São Paulo: Senac. 
Knafou, R. (1996). Turismo e Território: por uma abordagem científica do turismo. In: Rodrigues, A. A.B. Turismo e geografia: reflexões teóricas e enfoques regionais. São Paulo: HUCITEC. 62-74.

Ladwig, N. I. (2010). Os mapas cognitivos no Planejamento Estratégico e na Gestão Participativa do Turismo. VI Semintur. Seminário de Pesquisa em Turismo do Mercosul. Caxias do Sul: UCS.

Leno Cerro, F. (1993). Técnicas de evaluación del potencial turistico. Madrid: Ministerio de Industria, Comercio y Turismo. (Serie Libros sobre Turismo, 2).

Lima, I.; Godinho, R.; Azevedo, H. \& Teixeira, M. (2011). A informação e o mapeamento turísticos com base em Inventário Georreferenciado: O Caso do Município de Colinas do Sul. Revista Geográfica de América Central, 3, 1-19.

Madureira, M. \& Haag, V. (2011). O inventário da Oferta Turística no Programa de Regionalização do Turismo em Minas Gerais: uma problematização sobre os benefícios e limitações desse instrumento. Anais do VIII Seminário Anptur. Balneário de Camboriú/SC. Disponível em: https://www.anptur.org.br/anais/anais/files/8/124.pdf . Acesso em 15 dez 2019.

Moraes, C., Raimundo, S. \& Garcia, G. (2000). Turismo no Alto e Médio Tietê: possibilidades e infraestrutura. Salto/ SP: Inder.

Morin, E. (1999). O Método 3. O conhecimento do conhecimento. Porto Alegre: Editora Sulina.

Petrocchi, M. (2001). Gestão de Polos Turísticos. São Paulo: Futura.

Perantoni, A.; Viterbo, L. A. \& Nagabe, F. (2012). Inventário turístico: experiências turísticas acadêmicas com metodologias e práticas no planejamento do turismo no Pontal Paulista/SP. Anais do $5^{\circ}$ Congresso LatinoAmericano de Investigação Turística, 1-13.

Pimentel, T. \& Carvalho, F. C. (2003). Mapeando os modelos de planejamento turístico: em busca de refinamento teórico com vistas à intervenção qualificada. X Seminário Anptur, Caxias do Sul. Disponível em: https://docplayer.com.br/114916096-Mapeando-as-modelos-de-planejamento-turistico-em-busca-de-refi namento-teorico-com-vistas-a-intervencao-qualificada.html. Acesso em 20 nov. 2019.

Pinto, D. \& Moesch, M. M. (2006). Inventariação Turística por um Modelo de Superação Metodológica. IV SeminTUR - Seminário de Pesquisa em Turismo do MERCOSUL. Caxias do Sul, RS: Universidade de Caxias do Sul.

Pires, M. J. (2000). Levantamento de atrativos históricos em turismo: uma proposta metodológica. In: Lage, B. H. G.\& Milone, P. C. (Orgs.) Turismo: teoria e prática. São Paulo: Atlas.

OMT - Organização Mundial do Turismo. (1993). Introdução ao estudo do Turismo. São Paulo: Rocca.

Ruschmann, D. (1997). Turismo e Planejamento Sustentável: A proteção do meio ambiente. Campinas, São Paulo: Papirus.

Santos, M. (1996). A natureza do espaço. Técnica e tempo, razão e emoção. São Paulo: HUCITEC.

São Paulo. Secretaria de Turismo. (2015). Município de Interesse Turístico: Cartilha de orientação com a Lei 1261/15. Disponível em: https://www.turismo.sp.gov.br/publico/include/download.php?file=108 . Acessado em 20 jul 2019.

Smith, S. L. J. (1992). Geografía recreativa; investigación de potenciales turísticos. Tradução por Víctor M. Estrada Trilla. México: Trillas.

Stigliano, B.V \& César, P. A. B. (2006). Inventário turístico: primeira etapa da elaboração do plano de desenvolvimento turístico. Campinas, SP: Alínea.

Varisco, C. et all. (2014). El Relevamiento Turístico: de Cicatur a la Planificación Participativa. Anais Brasileiros de Estudos Turísticos / Universidade Federal de Juiz de Fora. 4 (3) , set /dez. Disponível em: www.editorauff.com.br/revista/index.php/abet/issue/current . Acessado em 20 jul. 2019.

Valls, J.-F. (2006). Gestão integral de destinos turísticos sustentáveis. Rio de Janeiro: Editora FGV. 
Caderno Virtual de Turismo, 2020, 20(1), ISSN: 1677-6976

\section{Notas}

[1] Título concedido pelo governo estadual, aos municípios que apresentarem característica turísticas e determinados requisitos relacionados a atratividade turística, infraestrutura e serviços turístico. 